\title{
Cane Molasses Graphene Quantum Dots Passivated by PEG Functionalization for Detection of Metal Ions
}

\author{
Ying Lou ${ }^{1}$, Jianying Ji ${ }^{1}$, Aimiao Qin ${ }^{1 *}$, Lei Liao ${ }^{2 *}$, Ziyuan ii $^{3}$, Shuoping Chen ${ }^{1}$, \\ Kaiyou Zhang ${ }^{1}$, Jun $\mathrm{Ou}^{1}$
}

${ }^{1}$ Key Lab New Processing Technology for Nonferrous Metals \& Materials Ministry of Education, College of Materials science and engineering, Guilin University of Technology, Guilin, 541004, P. R. China.

${ }^{2}$ College of Environmental Science and Engineering, Guilin University of Technology, Guilin, 541004, P. R. China.

${ }^{3}$ College of Chemistry and Bioengineering, Guilin University of Technology, Guilin, 541004, P. R. China

${ }^{*}$ Corresponding Authors:

2005032@glut.edu.cn(Aimiao Qin); fangqiu2001@163.com(Lei Liao) 
GQDs fluorescence probe for the detection of metal ions at different conditions; optimum synthesis conditions of GQDs; excitation wavelength dependence of GQDs, the degree of fluorescence quenching varies with the concentration of $\mathrm{Cu}^{2+}, \mathrm{Co}^{2+}, \mathrm{Ni}^{2+}, \mathrm{Mn}^{2+}$, and $\mathrm{Pb}^{2+}$ for PEG-GQDs; fluorescence decay curve of the GQDs, PEG-GQDs, and PEGGQDs in the presence of $\mathrm{Fe}^{3+}$, UV-vis absorption spectra of PEG-GQDs the presence of $\mathrm{Fe}^{3+}$, and the superposition of the UV-vis absorption spectra of PEG-GQDs and $\mathrm{Fe}^{3+}$ solution.

\section{Fluorescence detection of single metal ions at room temperature.}

For the quenching experiment of PEG-GQDs by $\mathrm{Fe}^{3+}, 200 \mathrm{~mL}$ of different concentrations of $\mathrm{Fe}^{3+}$ solution were mixed with $100 \mu \mathrm{L}$ of GQDs primary solution and then diluted to $5 \mathrm{~mL}$ with PEG-200 for fluorescence emission spectra test at room temperature. Similarly, the fluorescence response of different concentrations of $\mathrm{Cu}^{2+}$, $\mathrm{Co}^{2+}, \mathrm{Ni}^{2+}, \mathrm{Mn}^{2+}$ and $\mathrm{Pb}^{2+}$ to PEG-GQDs is also respectively performed using the above steps.

\section{Fluorescence detection of $\mathrm{Fe}^{3+}$ at $40{ }^{\circ} \mathrm{C}$}

In order to examine the effect of temperature on the fluorescence emission spectra of PEG-GQDs by $\mathrm{Fe}^{3+}, 100 \mu \mathrm{L}$ of GQDs primary solution was heated to $40{ }^{\circ} \mathrm{C}$ in a thermostatic water bath and diluted to $5 \mathrm{~mL}$ with PEG after adding $200 \mu \mathrm{L}$ of $\mathrm{Fe}^{3+}$ solutions of different concentrations.

\section{Fluorescence selectivity detection of $\mathrm{Fe}^{3+}$ in multiple metal ions}

To demonstrate the selectivity of PEG-GQDs toward $\mathrm{Fe}^{3+}, 200 \mu \mathrm{L}$ of different 
concentrations of $\mathrm{Fe}^{3+}$ solutions were added to a mixed solution of $100 \mu \mathrm{L}$ GQDs primary solution, $200 \mu \mathrm{L}$ EDTA(0.1M) and $200 \mu \mathrm{L}$ multiple metal ions solutions $\left(\mathrm{Cr}^{3+}, \mathrm{Ca}^{2+}, \mathrm{Al}^{3+}\right.$, $\left.\mathrm{Cu}^{2+}, \mathrm{Pb}^{2+}, \mathrm{Mn}^{2+}, \mathrm{Ag}^{+}, \mathrm{Ba}^{2+}, \mathrm{Co}^{2+}, \mathrm{Cd}^{2+}, \mathrm{Zn}^{2+}, \mathrm{Hg}^{2+}, \mathrm{Mg}^{2+}, \mathrm{Ni}^{2+}, 0.01 \mathrm{M}\right)$ and diluted to final volume of $5 \mathrm{~mL}$ with PEG-200. The fluorescence emission spectra should be performed after the solutions were kept for 10 minutes.

The $\mathrm{Fe}^{3+}$ detection limit was defined as LOD $=3 \sigma / \mathrm{m}$ where $\sigma$ is the standard deviation, $\mathrm{m}$ is the slope of the straight line in linear response region of the calibration curve. Similarly, the detection limit of other metal ions including $\mathrm{Cu}^{2+}, \mathrm{Co}^{2+}, \mathrm{Ni}^{2+}, \mathrm{Mn}^{2+}$, $\mathrm{Pb}^{2+}$ etc. are also determined using the above method.
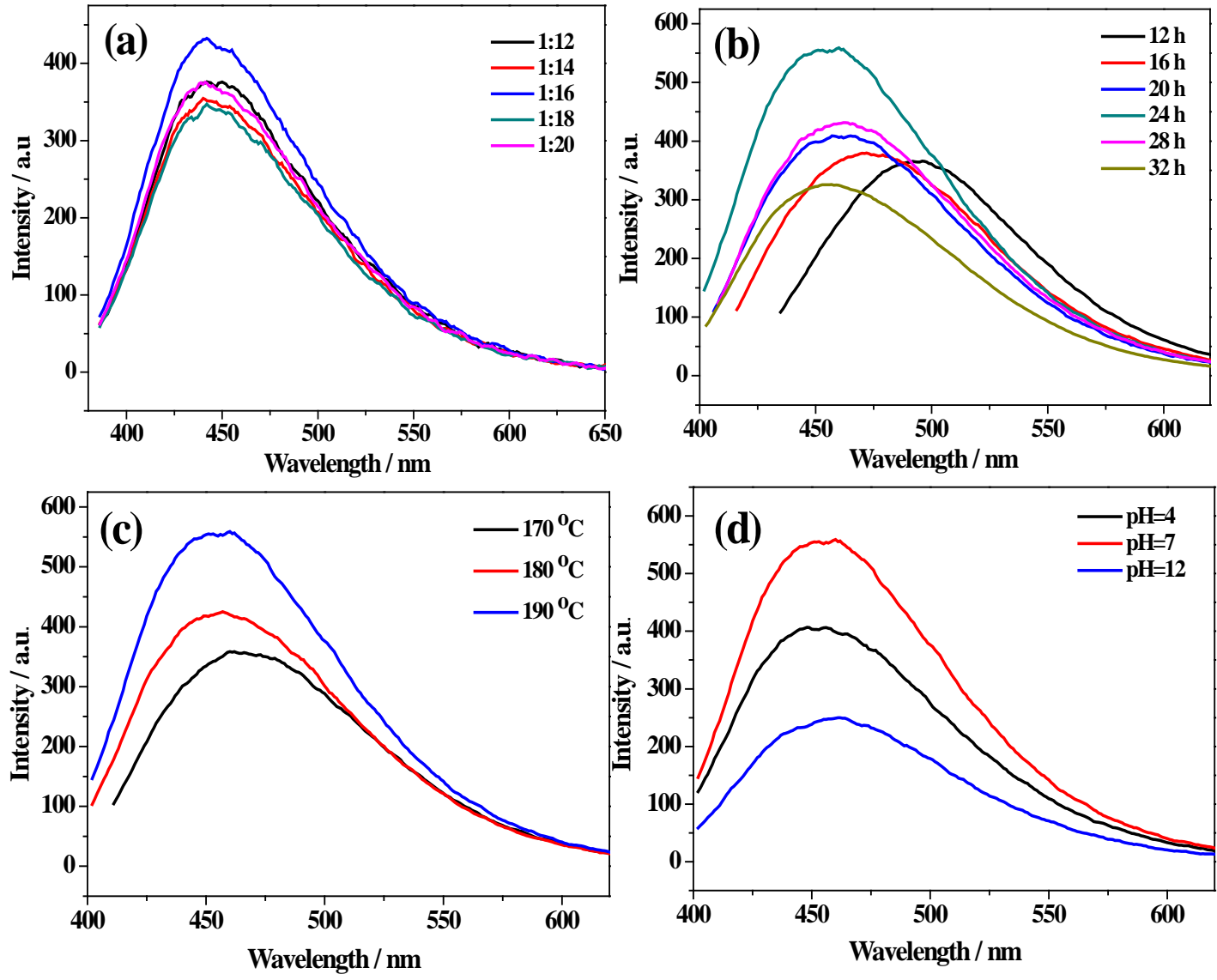
Figure S1 Effects of the volume ratio of cane molasses to ultrapure water(a), reaction time(b), reaction temperature(c) and $\mathrm{pH}$ value of the reaction system (d) on the fluorescence of GQDs, respectively. 

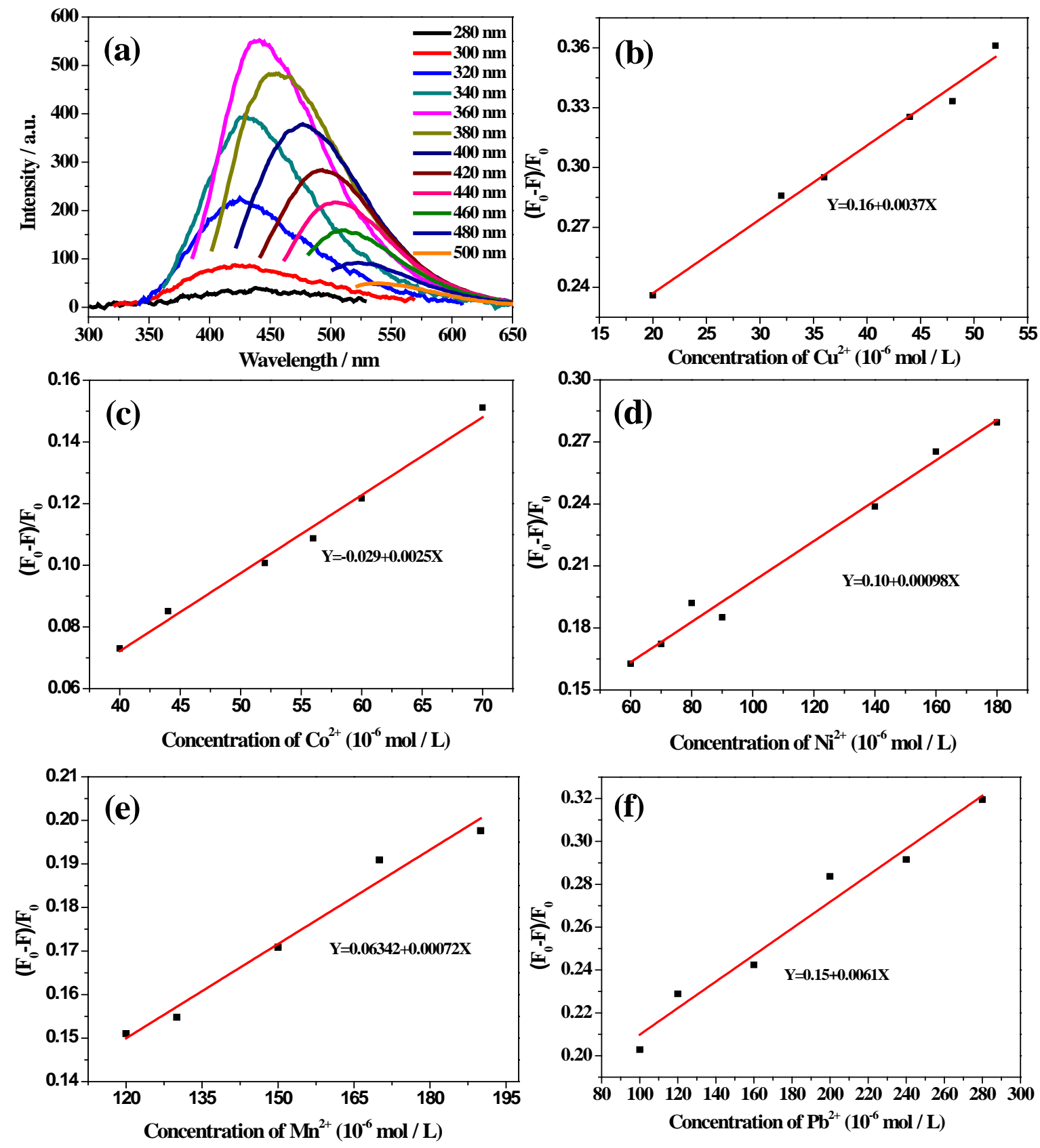

Figure S2 PL spectra of GQDs recorded for progressively longer excitation wavelengths from 280 to $500 \mathrm{~nm}$ (a); Calibration curves of the degree of fluorescence quenching [( $\mathrm{F}_{0}-$ F)/Fo ] of PEG-GQDs versus the concentrations of $\mathrm{Cu}^{2+}(\mathrm{b}), \mathrm{Co}^{2+}(\mathrm{c}), \mathrm{Ni}^{2+}(\mathrm{d}), \mathrm{Mn}^{2+}(\mathrm{e})$ and $\mathrm{Pb}^{2+}(\mathrm{f})$ ions , respectively. 

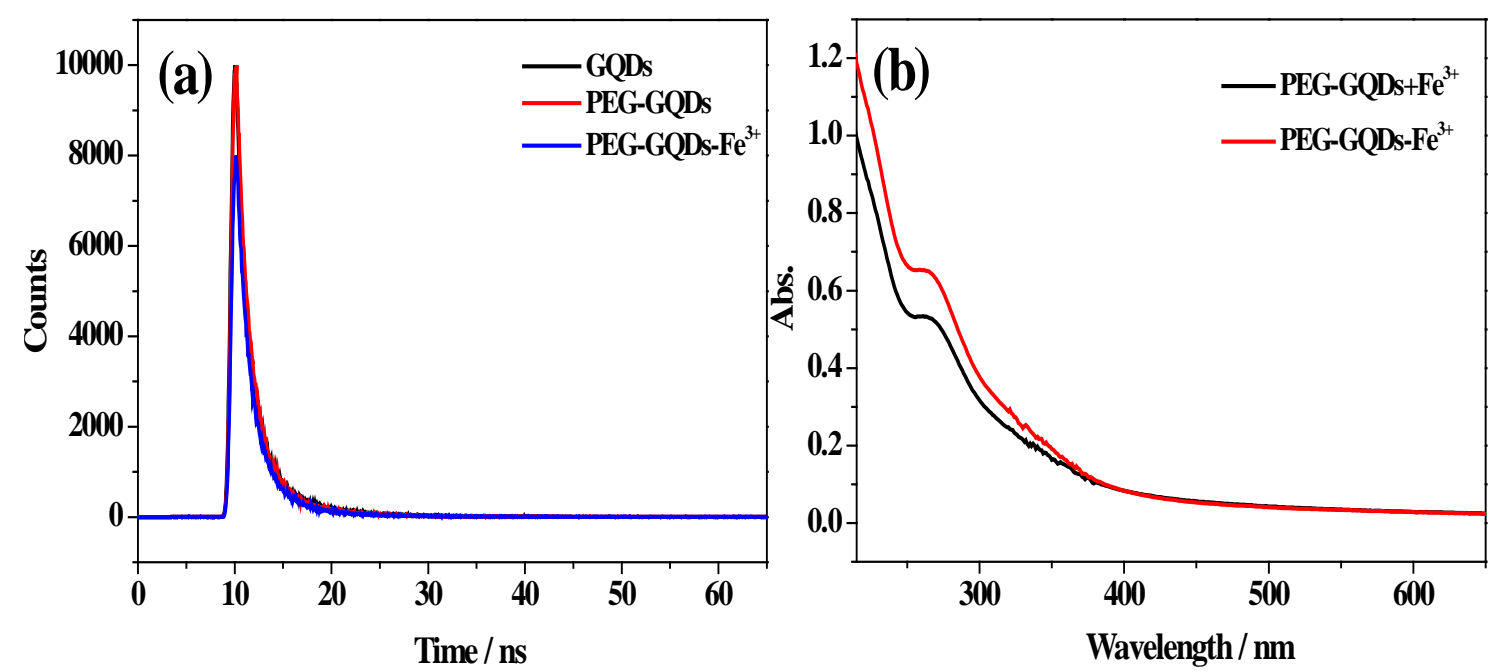

Figures S3 Time-resolved fluorescence decay curve of the GQDs, PEG-GQDs and PEGGQDs in the presence of $\mathrm{Fe}^{3+}(\mathrm{a})$; the UV-vis absorption spectra of PEG-GQDs in the presence of $\mathrm{Fe}^{3+}$ (red curve) and the superposition of the UV-vis absorption spectra of PEG-GQDs and $\mathrm{Fe}^{3+}$ solutions (black curve) (b). 